\title{
Age estimation in children by measurement of open apices in teeth: an Indian formula
}

\author{
Balwant Rai • J. Kaur • Mariano Cingolani • \\ Luigi Ferrante $\cdot$ Roberto Cameriere
}

Received: 24 September 2009 / Accepted: 27 January 2010

(C) Springer-Verlag 2010

\begin{abstract}
The aim of this paper is twofold: first, to evaluate an Indian sample by Cameriere's European formula; and second, if this formula turns out to be unsuitable, to study a specific formula for Indian children. Orthopantomographs taken from 480 Indian children (227 girls and 253 boys) aged between 3 and 15 years were analyzed. Following the pilot study, subjects' age was modeled as a function of gender $(g)$, region of country $(C)$, and morphological variables (predictors: $x_{5}$, the distance between the inner sides of the open apex of the second premolar divided by the tooth length;
\end{abstract}

Dr. Balwant Rai: Editor in Chief, Internet Journal of Dental ScienceUSA; Editor in Chief, Indian Journal of Forensic Odontology

\section{B. Rai $(\bowtie)$}

Ex-Lecture PDM Dental College,

Bahadurgarh, India

e-mail: raibalwant29@rediffmail.com

J. Kaur

Dr. Harbhajan Clinic,

Kapurthala, India

M. Cingolani

Institute of Legal Medicine, University of Macerata,

Via Don Minzoni 9,

62100 Macerata, Italy

\section{Ferrante}

Department of Clinical Medicine and Applied Biotechnologies, Polytechnic University of Marche,

Via Tronto 10/A,

60020 Ancona, Italy

R. Cameriere $(\square)$

AgEstimation project, Institute of Legal Medicine,

University of Macerata,

Via Don Minzoni 9,

62100 Macerata, Italy

e-mail: r.cameriere@unimc.it $s=x_{1}+x_{2}+x_{3}+x_{4}+x_{5}+x_{6}+x_{7}$, sum of normalized open apices; $N_{0}$, the number of teeth with root development complete. Results showed that all these variables except gender and second premolar contributed significantly to the fit so that all were included in the regression model, yielding the following linear regression formula:

Age $=9.402-0.879 C+0.663 N_{0}-0.711 s-0.106 s N_{0}$

where $C$ is a dummy variable equal to 0 for the center or north of India and 1 for the south. The above equation, with the variables considered, explained $89.7 \%\left(R^{2}=0.897\right)$ of total deviance. The median of the residuals (observed age minus predicted age) was -0.063 years, with an interquartile range of 1.10 years.

Keywords Forensic odontology - Age estimation Open apices $\cdot$ Mineralization $\cdot$ Multiple regression

\section{Introduction}

Age estimation is an important question in both forensic and clinical work. For forensic purposes, the problem of age estimation concerns how close true age is to the minimum age for criminal responsibility in various countries. According to Indian criminal law, subjects under 18 years old are exempt from criminal liability; minors less than 18 years old are subject to special criminal standards, and in specific circumstances, persons over 18 may be subject to the criminal standards applicable to minors under 18, in accordance with the Indian Minor Law. According to marriage law, young people have the right to marry at the age of 18 . In all such cases and in accordance with Indian criminal, marriage, and administrative laws, the prosecutor or corresponding admin- 
istrative authority is obliged to establish the age of the purported minor. A particular problem may arise when the law covering the adoption of children is applied if the date of the child's birth is uncertain. For example, Italian law establishes that there must be minimum and maximum differences in age (between 10 and 45 years) between the adopted child and the new parents. According to Indian adoption law, the child may be aged between 1 and 12 years but not more than 12 years.

The most frequently used method for age estimation in children is the study of radiographs of teeth and hand/wrist [1-14]. In 2001 and recently in 2008, the Study Group on Forensic Age Diagnostics stressed the study of these areas as fundamental for age estimation $[15,16]$. In particular, as regards teeth, Demirjian's method is the most frequently used [7]. A number of methods have been proposed to determine dental age, but the system developed by Demirjian has gained wide acceptance. Two studies testing the applicability of this method in an Indian sample showed an overestimation of age and concluded that it cannot be applied to Indian children [17, 18]. In 2006, a new method was studied, involving the measurement of open apices in maxillary teeth [19], tested, and published in a European sample [20]. The aim of the present paper was twofold: first, to evaluate an Indian sample by means of Cameriere's formula and, if this formula turned out to be unsuitable, to study a specific formula for Indian children.

\section{Materials and methods}

A sample of orthopantomographs of healthy children living in the north (Haryana, New Delhi), center (Madhya Pradesh), and south (Kerala, Pondicherry) of India, aged between 3

Table 1 Age and gender distribution of study subjects

\begin{tabular}{lrrr}
\hline Age (years) & Females & Males & Total \\
\hline 3 & 4 & 1 & 5 \\
4 & 12 & 14 & 26 \\
5 & 17 & 23 & 40 \\
6 & 26 & 27 & 53 \\
7 & 21 & 23 & 44 \\
8 & 20 & 19 & 39 \\
9 & 13 & 19 & 32 \\
10 & 18 & 18 & 36 \\
11 & 20 & 18 & 38 \\
12 & 26 & 26 & 52 \\
13 & 24 & 31 & 55 \\
14 & 24 & 31 & 55 \\
15 & 3 & 3 & 6 \\
Total & 228 & 252 & 480 \\
\hline
\end{tabular}

Table 2 Distribution of study subjects in three areas of India

\begin{tabular}{lccc}
\hline Country & Females & Males & Total \\
\hline North & 79 & 77 & 156 \\
Center & 70 & 80 & 150 \\
South & 78 & 96 & 174 \\
& 227 & 253 & 480 \\
\hline
\end{tabular}

and 15 years and taken during a course of diagnosis and treatment, was selected (Tables 1,2). The orthopantomographs were taken as part of routine treatment between 2000 and 2006. Any radiographs which were unclear or which showed hypodontia, gross pathology, and/or previous orthodontic treatment were excluded. The chronological age of each subject was calculated by subtracting the date of the radiograph from the date of birth. Radiographs were in digital form or were digitalized on a scanner, and images were recorded on computer files, processed by a computeraided drafting program (Adobe Photoshop 7). The method is fully explained in Cameriere et al. [19]. Briefly, radiographs of left permanent mandibular teeth, except wisdom teeth, with the apical ends of the roots completely closed $\left(N_{0}\right)$, were examined. Teeth with incomplete root development, i.e., with open apices, were also examined. For teeth with one root, the distance $\mathrm{A} i, i=1, \ldots, 5$, between the inner side of the open apex was measured. For example, A1 denotes the distance between the inner side of the open apex of the first incisor. For teeth with two roots, $\mathrm{A} i, i=6,7$, the sum of the distances between the inner sides of the two open apices was evaluated. To take into account the effect of possible differences in magnification and angulation among radiographs, measurements were normalized by dividing by tooth length $(\mathrm{L} i, i=1, \ldots, 7)$. Lastly, dental maturity was evaluated with the normalized measurements of the seven permanent left mandibular teeth $\left(x_{\mathrm{i}}=\mathrm{A} i / \mathrm{L} i, i=1, \ldots, 7\right)$, the sum of normalized open apices $\left(s=x_{1}+x_{2}+x_{3}+x_{4}+x_{5}+\right.$ $\left.x_{6}+x_{7}\right)$, and the number $\left(N_{0}\right)$ of teeth with root development complete. Measurements were carried out by two

Table 3 Stepwise regression analysis, predicting chronological age from chosen predictors

\begin{tabular}{lcccr}
\hline Coefficients & Value & SE & $t$ value & \multicolumn{1}{l}{$p$} \\
\hline Intercept & 9.37 & 0.151 & 62.057 & $<0.001$ \\
Region & -0.881 & 0.086 & -10.296 & $<0.001$ \\
Gender & 0.133 & 0.082 & 1.61 & 0.108 \\
$s$ & 0.657 & 0.024 & 27.806 & $<0.001$ \\
$N_{0}$ & -0.684 & 0.054 & -12.549 & $<0.001$ \\
$x_{5}$ & -0.217 & 0.292 & -0.745 & 0.457 \\
$s \cdot N_{0}$ & -0.104 & 0.034 & -3.034 & 0.003 \\
\hline$s \cdot N_{0}=$ interaction between variables $s$ and $N_{0}$ & &
\end{tabular}


Table 4 Stepwise regression analysis, predicting chronological age for Indian population

\begin{tabular}{lcccc}
\hline Coefficients & Value & SE & $t$ value & $p$ \\
\hline Intercept & 9.402 & 0.141 & 66.496 & $<0.001$ \\
Region & -0.879 & 0.085 & -10.287 & $<0.001$ \\
$s$ & 0.663 & 0.023 & 29.05 & $<0.001$ \\
$N_{0}$ & -0.711 & 0.037 & -19.227 & $<0.001$ \\
$s \cdot N_{0}$ & -0.106 & 0.034 & -3.128 & 0.002 \\
\hline
\end{tabular}

different observers. Assessment of inter-observer reliability was checked on an independent sample of 27 panoramic radiographs.

\section{Statistical analysis}

For each individual, all the morphological variables, $x_{5}, s$, $N_{0}$, gender, and region (north, center, and south India) were entered in an EXCEL file to be used as predictive variables for age estimation in subsequent statistical analysis. Chronological age, calculated by subtracting the date of the radiograph from the date of birth, was also recorded.

The interobserver reliability of the sum of normalized open apices $(s)$ was studied by means of the concordance correlation coefficient, and $\mathrm{k}$ statistics were used to measure the interobserver reliability of the number of the seven right permanent mandibular teeth with root development complete $\left(N_{0}\right)$.

In order to obtain an estimate of age as a function of the morphological variables and subjects' gender and nationality, a multiple linear regression model with first-order interactions was developed by selecting those variables which contributed significantly to age estimations according to the stepwise selection method. An analysis of covariance was then applied to study possible interactions between significant morphological variables and gender and region. Statistical analysis was performed with S-PLUS 6 statistical programs (S-PLUS 6.1 for Windows, Professional Edition, Release 1). The significance threshold was set at $5 \%$.

\section{Results}

There were no statistically significant interobserver differences between the paired sets of measurements carried out on the re-examined panoramic radiographs. In fact, in the seven right permanent mandibular teeth with root development complete $\left(N_{0}\right)$, no misfit was observed between the two measurements made by the observers, i.e., $k=1$. For the paired sets of measurements of the sum of normalized open apices $(s)$, the estimated concordance correlation coefficient ( \pm standard deviation) was $\rho_{c}=0.989 \pm 0.006$.

Following the results reported in [19], subjects' age was modeled as a function of gender $(g)$, region of country $(C)$, and morphological variables: $x_{5}$ (second premolar), $s, N_{0}$, and the first-order interaction between $s$ and $N_{0}$.

Statistical analysis showed that not all the variables used for the European model were significant predictors of age in the Indian sample (Table 3). In particular, no gender or second premolar variables were significant (Table 4). As regard the region variable, regression analysis pointed out that north and central regions were not significant but the
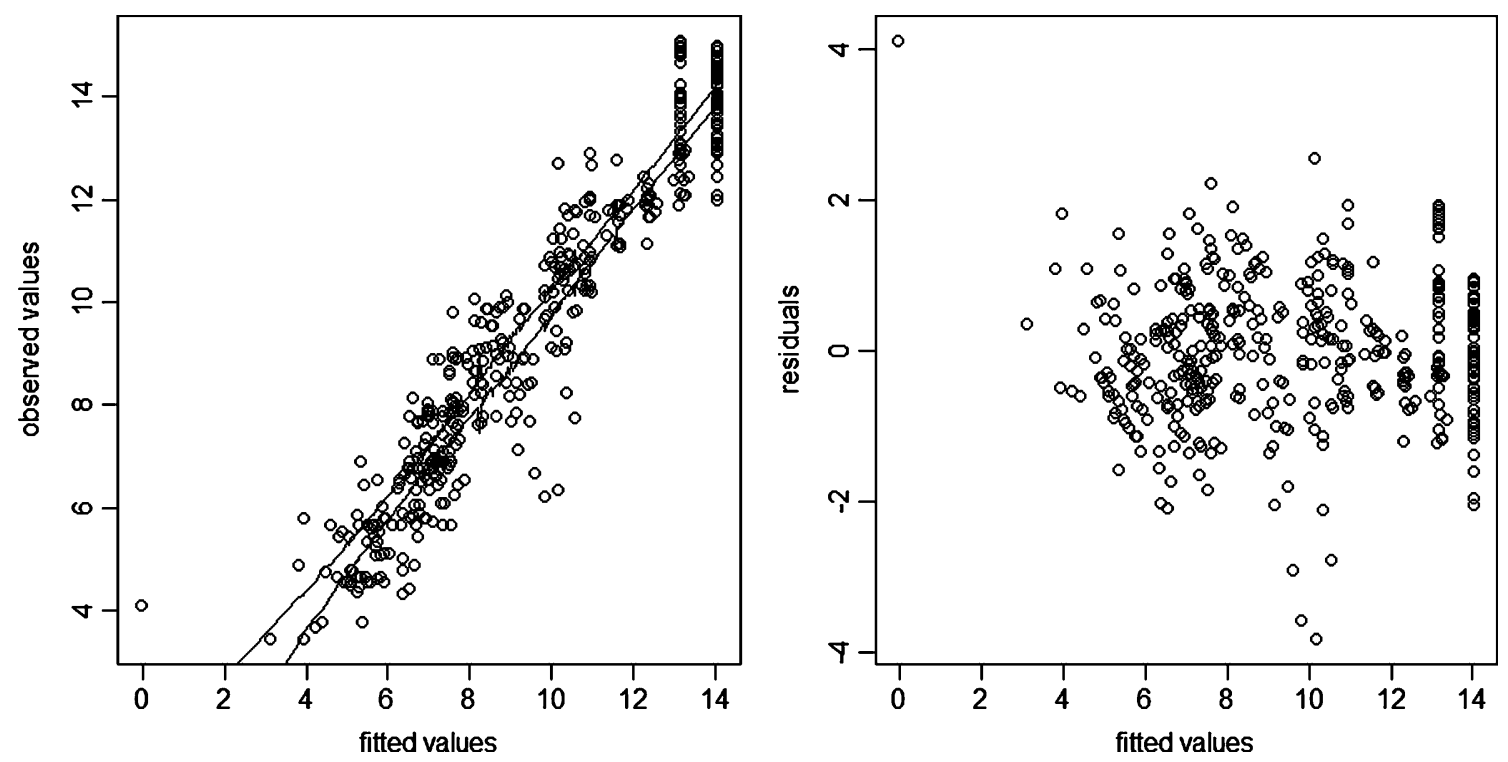

Fig. 1 Plots of residuals against fitted values (right panel) and of observed against predicted values (left panel) using regression model (1) 
south region was. Consequently, we pooled north and central sample together.

The results show that these variables, partly unlike the variables used for the European formula, contributed significantly to the fit, yielding the following linear regression formula for the Indian population:

Age $=9.402-0.879 C+0.663 N_{0}-0.711 s-0.106 s N_{0}$

where $C$ is a variable, 0 for central or north India and 1 for the south. Equation 1, with the considered variables, explained $89.7 \%\left(R^{2}=0.897\right)$ of total deviance. The median of the residuals (observed age minus predicted age) was 0.063 years, with an interquartile range of 1.10 years.

The residual plot (Fig. 1, right panel) shows no obvious pattern. The observed versus predicted plot (Fig. 1, left panel) shows that the regression model fits the trend of the data reasonably well. Hence, both diagnostic plots support our chosen model.

\section{Discussion}

The growth of a child may be influenced by several different factors (ethnic, social, nutritional, etc.). Among the several anatomical districts usually examined, the teeth are less influenced by these factors. Nevertheless, the various methods of age estimation based on teeth do not provide a common formula for the whole world [24-26]. Also in the present research, a formula yielding correct values for a European sample could not be applied to an Indian one, and a new formula is necessary, and any new formula should take into account differences between central/north and south India. In a country as large as India, the factors previously cited (ethic, social, nutritional, etc.) probably influence children's growth differently. In addition, no statistical differences in dental age estimation were found between male and female samples. It is possible that the poor nutritional status of Indian adolescents, especially girls, has important implications in terms of their capacity for physical work and adverse reproductive outcomes, as was in fact observed in one study [17] but contrary to the results found in another [18]. Hence, the maturation of girls and boys in India may be said to occur at about the same time because the early maturation of girls, when compared with boys, may be offset by malnutrition and the greater amount of physical work required of them. The results found in this work, like those of others, indicate that more attention should be focused on the possible differences between children of different origins. In fact, all differing factors may be important for age estimation and could make the European formula inappropriate. Further studies will be carried out to apply Cameriere's formula to a new Indian sample, to test a new Asian sample, and to study the effects of the nutrition factor on the Indian formula.

\section{References}

1. Haaviko K (1970) The formation and the alveolar and clinical eruption of the permanent teeth. An orthopantomographic study. Thesis Suom Hamm A Slaak Toim 66:103-170

2. Nystrom M, Peck L, Kleemola-Kujala E, Evalahti M, Kataja M (2000) Age estimation in small children: reference values based on counts of deciduous teeth in Finns. Forensic Sci Int 110:179-188

3. Flores-Mir C, Mauricio FR, Orellana MF, Major PW (2005) Association between growth stunting with dental development and skeletal maturation state. Angle Orthod 75:935-940

4. Nielson HG, Ravn JJ (1976) A radiographic study of mineralization of permanent teeth in a group of children aged 3-7 years. Scand J Dent Res 84:109-118

5. Staaf V, Mornstud H, Welander U (1991) Age estimation based on tooth development: a test of reliability and validity. Scand J Dent Res 99:281-286

6. Hagg U, Matsson L (1985) Dental maturity as an indicator of chronological age: the accuracy and precision of three methods. Eur J Orthod 7:25-34

7. Demirijian A, Goldstein H, Tanner JM (1973) A new system of dental age assessment. Hum Biol 45:211-227

8. Olze A, van Niekerk P, Schmidt S, Wernecke KD, Rosing FW, Geserick G, Schmeling A (2006) Studies on the progress of thirdmolar mineralization in a Black African population. Homo 57:209-217

9. Cameriere R, Ferrante L, Mirtella D, Cingolani M (2006) Carpals and epiphyses of radius and ulna as age indicators. Int $\mathrm{J}$ Legal Med 120:143-146

10. Schmidt S, Baumann U, Schulz R, Reisinger W, Schmeling A (2008) Study of age dependence of epiphyseal ossification of the hand skeleton. Int J Legal Med 122:51-54

11. Cameriere R, Ferrante L (2008) Age estimation in children by measurement of carpals and epiphyses of radius and ulna and open apices in teeth: a pilot study. Forensic Sci Int 174:60-63

12. Schmidt S, Nitz I, Schulz R, Schmeling A (2008) Applicability of the skeletal age determination method of Tanner and Whitehouse for forensic age diagnostics. Int J Legal Med 122:309-314

13. Cruz-Landeira A, Linares-Argote J, Martínez-Rodríguez M, Rodríguez-Calvo MS, Otero XL, Concheiro L (2009) Dental age estimation in Spanish and Venezuelan children. Comparison of Demirjian and Chaillet's scores. Int J Legal Med 2009 Oct 28

14. Knell B, Ruhstaller P, Prieels F, Schmeling A (2009) Dental age diagnostics by means of radiographical evaluation of the growth stages of lower wisdom teeth. Int J Legal Med 123:465-469

15. Schmeling A, Olze A, Reisinger W, Geserick G (2001) Age estimation of living people undergoing criminal proceedings. Lancet 358:89-90

16. Schmeling A, Grundmann C, Fuhrmann A, Kaatsch HJ, Knell B, Ramsthaler F, Reisinger W, Riepert T, Ritz-Timme S, Rösing FW, Rötzscher K, Geserick G (2008) Criteria for age estimation in living individuals. Int J Legal Med 122:457-460

17. Koshy S, Tandon S (1998) Dental age assessment: the applicability of Demirjian's method in south Indian children. Forensic Sci Int 94:73-85

18. Anand K, Kant S, Kapoor SK (1999) Nutritional status of adolescent school children in rural north India. Indian Pediatr $36: 810-816$

19. Cameriere R, Ferrante L, Cingolani M (2006) Age estimation in children by measurement of open apices in teeth. Int J Legal Med 120(1):49-52 
20. Cameriere R, Ferrante L, Cingolani M (2007) Age estimation in children by measurement of open apices in teeth: a European formula. Int J Legal Med 121:449-553

21. Cameriere R, Flores-Mir C, Mauricio F, Ferrante L (2007) Effects of nutrition on timing of mineralization in teeth in a Peruvian sample by the Cameriere and Demirjian methods. Ann Hum Biol 34:547-556

22. Olze A, Taniguchi M, Schmeling A, Zhu BL, Yamada Y, Maeda H, Geserick G (2003) Comparative study on the chronology of third molar mineralization in a Japanese and a German population. Leg Med 5(Suppl 1):S256-S260
23. TeMoananui R, Kieser JA, Herbison GP, Liversidge HM (2008) Estimating age in Maori, Pacific Island, and European children from New Zealand. J Forensic Sci 53:401-404

24. Liversidge HM, Speechly T, Hector MP (1999) Dental maturation in British children: are Demirjian's standards applicable? nt J Paediatr Dent 9:263-269

25. Qudeimat MA, Behbehani F (2009) Dental age assessment for Kuwaiti children using Demirjian's method. Ann Hum Biol 23:1-10

26. Tunc ES, Koyuturk AE (2008) Dental age assessment using Demirjian's method on northern Turkish children. Forensic Sci Int $175: 23-26$ 